\title{
Stimulus design is an obstacle course: 560 matched literal and metaphorical sentences for testing neural hypotheses about metaphor
}

\author{
Eileen R. Cardillo, Gwenda L. Schmidt, Alexander Kranjec, and Anjan ChatterJee \\ University of Pennsylvania, Philadelphia, Pennsylvania
}

\begin{abstract}
Despite the ubiquity and importance of metaphor in thought and communication, its neural mediation remains elusive. We suggest that this uncertainty reflects, in part, stimuli that have not been designed with recent conceptual frameworks in mind or that have been hampered by inadvertent differences between metaphoric and literal conditions. In this article, we begin addressing these shortcomings by developing a large, flexible, extensively normed, and theoretically motivated set of metaphoric and literal sentences. On the basis of the results of three norming studies, we provide 280 pairs of closely matched metaphoric and literal sentences that are characterized along 10 dimensions: length, frequency, concreteness, familiarity, naturalness, imageability, figurativeness, interpretability, valence, and valence judgment reaction time. In addition to allowing for control of these potentially confounding lexical and sentential factors, these stimuli are designed to address questions about the role of novelty, metaphor type, and sensory-motor grounding in determining the neural basis of metaphor comprehension. Supplemental data for this article may be downloaded from http://brm.psychonomic-journals .org/content/supplemental.
\end{abstract}

Metaphor is not just for poets. Over the last 20 years, cognitive scientists have recognized the pervasiveness of metaphor in ordinary language. Metaphor's universality and, perhaps more importantly, the systematic ways in which it is used, appear to reflect something important about the structure of the mind (Boroditsky, 2000; Gentner, 2003; Lakoff \& Johnson, 1980). In order to appreciate this claim about the importance of metaphor, we must first move beyond traditional literary definitions. At the most prosaic level, metaphor refers simply to the ways in which we can conceptualize one domain in terms of another superficially dissimilar domain. This often involves the figurative use of a noun, as in The data are a headache. In other cases, the basis for the metaphor might be a verb phrase, as in The scientists got over their disappointment. Both kinds of metaphor occur frequently in language and are indicative of the ubiquity and heterogeneity of metaphor. Despite this prevalence of use and consensus in the cognitive sciences about the importance of metaphoric thought and expression, the neural substrates of metaphor are surprisingly murky. We believe that this uncertainty reflects, in part, the influence of uncontrolled properties of the stimuli used in past research. In this article, we attempt to address these shortcomings by developing stimuli specifically tailored to cognitive neuroscience methods and neural hypotheses about metaphor.

Although now largely discounted, early accounts of metaphor comprehension assumed the existence of dis- tinct processes required to understand literal and figurative language (Grice, 1975; Searle, 1979), with presumably different neural bases for each. Initial investigations with brain-injured patients supported this conjecture, suggesting a critical role for the right hemisphere in the comprehension of metaphor (Brownell, Potter, Michelow, \& Gardner, 1984; Brownell, Simpson, Bihrle, Potter, \& Gardner, 1990; Winner \& Gardner, 1977). The accumulated evidence is less clear than this now familiar story suggests, however, with early studies suffering from several methodological weaknesses (e.g., small numbers of items, anatomical distinctions lacking precision, task confounds; for a review, see Schmidt, Kranjec, Cardillo, $\&$ Chatterjee, 2010). More recent work with patients has not been as vulnerable to these limitations and, coupled with the advent of neuroimaging and transcranial magnetic stimulation, has challenged this straightforward assignment of hemispheric duties. Rather, both the left and right hemispheres have now been implicated in the processing of metaphor, and some research suggests that the right hemisphere is not uniquely sensitive to figurativeness per se. However, at this point, no single brain area or discrete network has emerged as uniquely responsive to metaphoric language (Schmidt et al., 2010).

These inconsistencies likely reflect, in part, a failure to properly consider factors of noninterest that nonetheless tend to vary between metaphoric and literal conditions. In the review that follows, we discuss the confounding in-

E. R. Cardillo, eica@mail.med.upenn.edu 
fluence of several psycholinguistic variables (frequency, concreteness, length, imageability, naturalness, and interpretability) that likely make the metaphorical sentences used in previous studies more difficult to process than the literal sentences. Other differences between studies may be attributed to more conceptual factors that have not yet been adequately addressed (Schmidt et al., 2010). Specifically, we argue for the theoretical importance of metaphor novelty and type when investigating the neural substrates for metaphor. Following this discussion, we present data from three norming tasks used to develop a set of metaphoric and literal stimuli that we believe to be well suited to address these methodological and theoretical issues in future empirical work on the neural basis of metaphor.

\section{Difficulty}

Previous comparisons between literal and metaphorical processing have likely been complicated by differences in processing difficulty related to uncontrolled lexical and sentential characteristics. Behavioral studies at the single-word level consistently demonstrate that frequency, concreteness, and length affect the ease (i.e., speed) with which words are accessed (Balota, Yap, \& Cortese, 2006). Neuroimaging studies also demonstrate the importance of these three factors in driving neural activity in single-word tasks. Low-frequency words are read more slowly and also more strongly engage language-sensitive areas of the brain, including the left prefrontal cortex, middle and superior temporal gyri, and the so-called "visual word-form area" of the fusiform gyrus (for a review, see Hauk, Davis, \& Pulvermüller, 2008). Although concreteness can be captured along a continuum with abstractness, unlike low-frequency words, abstract words do not simply take longer to read and more strongly engage the same brain areas recruited by concrete words. Rather, concrete and abstract words show both shared and distinct neural substrates even after controlling for reaction time differences (Binder, Medler, Desai, Conant, \& Liebenthal, 2005; see also Fiebach \& Friederici, 2003; Scott, 2004). As for length, longer words generally elicit slower responses in behavioral tasks (Balota et al., 2006). Such processing time differences are not insignificant; the BOLD signal in fMRI is especially sensitive to the time taken to perform a task, and activity in many regions of both hemispheres are independently modulated by reaction time in language tasks (e.g., Binder, Medler, et al., 2005; Binder, Westbury, McKiernan, Possing, \& Medler, 2005).

The impact of the frequency, concreteness, and length of words on neural activity when they are embedded in sentences or narratives has not generally been addressed. However, the modulatory effects of these factors at the single-word level strongly suggest their continued influence at higher levels of language processing, an inference supported by several recent studies (Keller, Carpenter, \& Just, 2001; Prat, Keller, \& Just, 2007; Yarkoni, Speer, Balota, McAvoy, \& Zacks, 2008). Similarly, other features of sentences such as imageability (Just, Newman, Keller,
McEleney, \& Carpenter, 2004), syntactic complexity (Constable et al., 2004; Friederici, Fiebach, Schlesewsky, Bornkessel, \& von Cramon, 2006; Just, Carpenter, Keller, Eddy, \& Thulborn, 1996), and semantic plausibility (Cardillo, Aydelott, Matthews, \& Devlin, 2004; Kuperberg et al., 2003; Menenti, Petersson, Scheeringa, \& Hagoort, 2009) also alter neural demands in areas both within and beyond the classic language areas of the brain. The more syntactically complex and the less semantically plausible or predictable a sentence, the more time it requires to be processed and the more strongly it activates the lefthemisphere language network and its right-hemisphere homologues. With respect to imageability, signal intensity is positively correlated in some areas (e.g., the intraparietal sulcus) and negatively in others (e.g., the middle and superior temporal gyri).

These patterns indicate that qualities that make sentences more challenging to understand often make them slower to read and increase neural activation. Accordingly, these findings suggest two other sentence-level properties - naturalness and interpretability - that are important to control, since both factors are also likely to affect reading times. Naturalness refers to the normality of an utterance, or the likelihood that a speaker might spontaneously express an idea in a particular manner. Literal sentences are likely to seem more natural than metaphors, especially if the metaphors are not very familiar, but naturalness is rarely directly addressed in neuroimaging studies. Interpretability refers to the ease with which a clear meaning can be derived from an expression. It is not operationalized in a consistent way across studies and, more problematic, is likely to be lower for metaphoric stimuli than for literal items.

Taken together, it appears that the BOLD signal in fMRI studies is sensitive to a range of lexical and sentential characteristics not typically controlled for in neuroimaging studies of metaphor, all of which influence processing time. Although time on task is only an indirect indicator of cognitive effort, it is a critical dimension to address. The extent to which previous reports of increased neural activity in certain regions associated with metaphors reflects processing difficulty rather than figurativeness remains unknown since, with few exceptions (Bottini et al., 1994; Chen, Widick, \& Chatterjee, 2008; Lee \& Dapretto, 2006; Mashal, Faust, Hendler, \& Jung-Beeman, 2009; Rapp, Leube, Erb, Grodd, \& Kircher, 2004; Stringaris, Medford, Giampietro, Brammer, \& David, 2007), condition differences in reaction time have not been measured, controlled, or reported.

\section{Novelty}

Another critical factor contributing to the empirical muddle is how the processing of metaphors changes over time. Novel metaphoric uses of words may gain in popularity, with those same figurative senses that were once so creative becoming familiar and fairly unremarkable with increased use. Bowdle and Gentner (2005) provide behavioral evidence that this shift from novel to conventional usage is accompanied by a shift in how 
metaphors are understood, a process they describe as the career of metaphor. Although the career of metaphor account is motivated by behavioral data, the implication of this proposed shift in cognitive processing with increased familiarity (i.e., diminished novelty) is that it is paralleled by a shift in neural recruitment. Similarly, the hypothesis that the right hemisphere may be sensitive to novelty rather than metaphoricity, per se, has been recently proposed to clarify the neural evidence. In many neuroimaging and all patient studies to date, conventional or idiomatic expressions were considered. Those studies in which novel metaphors are considered are more likely to implicate the right hemisphere (Arzouan, Goldstein, \& Faust, 2007; Bottini et al., 1994; Mashal, Faust, \& Hendler, 2005; Mashal, Faust, Hendler, \& Jung-Beeman, 2007; Pobric, Mashal, Faust, \& Lavidor, 2008; Sotillo et al., 2005). Less promising for the novelty hypothesis, nearly as many neuroimaging studies in which novelty/familiarity was manipulated have not found right-hemisphere engagement during processing of novel metaphors as have found it (Kircher, Leube, Erb, Grodd, \& Rapp, 2007; Mashal et al., 2009; Rapp et al., 2004; Rapp, Leube, Erb, Grodd, \& Kircher, 2007; Shibata, Abe, Terao, \& Miyamoto, 2007).

One reason that these studies with novel metaphors have differed in their findings may be related to variability in how their stimuli were normed on the previously mentioned lexical and sentential characteristics. A further possible explanation for the discrepant findings is that the right hemisphere is sensitive to the salience or prominence of a metaphorical interpretation, rather than the novelty or figurativeness of the utterance (Giora, 1999). Giora, Zaidel, Soroker, Batori, and Kasher (2000) have proposed that a literal interpretation may be more prominent (i.e., more quickly generated) than the figurative meaning of unfamiliar metaphors, and that the right hemisphere may play an important role in generating the novel, nonsalient interpretation (which frequently happens to also be the figurative one).

Alternatively, the inconsistencies may reflect differences related to generating metaphorical meaning at the level of words versus that of sentences (Mashal et al., 2009). For the most part, in the studies indicating righthemisphere sensitivity to novelty, metaphorical word pairs of high and low conventionality have been compared (bright student vs. pearl tears), whereas those in which right-hemisphere sensitivity to novelty was not found have featured sentence stimuli. Mashal et al. (2009) suggested that although the right hemisphere may be biased to extract novel meanings entailed by two uncommonly paired words, the syntactic and semantic integration demands imposed by novel sentences may necessitate the recruitment of the language-dominant left hemisphere. Although no patient studies have considered novel metaphor comprehension, work by Kempler and colleagues (Kempler, Van Lancker, Marchman, \& Bates, 1999; Van Lancker \& Kempler, 1987) is consistent with this suggestion. In two studies, right-hemisphere-injured patients performed worse than left-hemisphere-injured patients on a sentence-picture matching task involving familiar idiomatic expressions (He's turning over a new leaf) but outperformed left-hemisphere-injured patients when tested on novel literal sentences (He's sitting deep in the bubbles). Although these studies cannot disentangle the effects of novelty from figurativeness, they are consistent with the notion that the left, not the right, hemisphere is required for handling novel meaning at the sentence level.

A recent fMRI study in which novel sentence-level metaphors taken from poetry were considered is also suggestive of this proposed difference in how the brain processes novel lexical and sentential metaphors (Mashal et al., 2009), but thus far lexical and sentential metaphors have not been directly compared in any neuroimaging study, nor have conventional and novel metaphors at the sentence level been contrasted or neural changes with increased experience with a particular metaphoric sense of a word been considered. Thus, determining hemispheric contributions to the processing of novel metaphors requires sentences that vary in familiarity but for which a metaphorical interpretation is still more salient than a literal one. In addition, novelty may have different consequences for the processing of different types of metaphor.

\section{Metaphor Type}

Metaphor is not a unitary construct (Chen et al., 2008). As any conversation quickly reveals, even the least poetic of speakers is likely to use a variety of metaphoric expressions. These different types of metaphor reflect differences in the class of word that is being used figuratively (the base term). Although the majority of metaphor research has addressed the metaphorical extension of nouns, or nominal metaphors (The stock is a rollercoaster), other parts of speech are also frequently used metaphorically. For example, we extend verbs metaphorically in predicate metaphors (The stock soared), prepositions in locative metaphors (The stock is down), and adjectives in attributive metaphors (the hot stock).

For two reasons, these differences in the nature of metaphor base terms are likely to be paralleled by different neural substrates. First, the cognitive demands required for the comprehension of their figurative use is likely to differ. Nominal metaphors, for instance, appear to be understood via a process of comparison (Gentner, Bowdle, Wolff, \& Boronat, 2001), categorization (Glucksberg, 2003), or some combination of the two (Bowdle $\&$ Gentner, 2005). In contrast, predicate metaphors may be understood by a process of abstraction, whereby the concrete, sensory-motor features of a verb are stripped away, retaining only a few core conceptual attributes during its metaphoric use (Chen et al., 2008; see also Torreano, Cacciari, \& Glucksberg, 2005). Second, both fMRI and patient studies have demonstrated differences in the brain areas important for literal processing of these word classes. Noun processing is typically associated with inferior occipitotemporal cortex; verbs with posterolateral temporal, prefrontal, and motor cortex; and prepositions with parietal cortices (for reviews, see Martin, Unger- 
leider, \& Haxby, 2000; Chatterjee, 2008; and Kemmerer, 2006, respectively).

Importantly, these different neural signatures for nouns, verbs, and prepositions are very similar to those areas involved in the perception of objects (Ishai, Ungerleider, Martin, \& Haxby, 2000; Ishai, Ungerleider, Martin, Schouten, \& Haxby, 1999), actions (Kable \& Chatterjee, 2006; Kable, Kan, Wilson, Thompson-Schill, \& Chatterjee, 2005; Tranel, Manzel, Asp, \& Kemmerer, 2008), and spatial relations (Amorapanth, Widick, \& Chatterjee, 2009; Kosslyn, Maljkovic, Hamilton, Horowitz, \& Thompson, 1995), respectively. Thus, there is growing evidence that linguistic representations are stored in the same cortex responsible for the perception of their concrete referents or in overlapping or adjacent cortex (Pulvermüller, 2005; Simmons \& Barsalou, 2003; Thompson-Schill, 2003). Such sensory-motor grounding for the literal senses of words suggests that the neural mediation of their metaphorical extensions may similarly recruit relevant sensory or motor regions (Gibbs, 2006). Or it may be that the imperfect overlap between activations elicited by perceptual and linguistic stimuli indicates a neural principle of organization by which more abstract representations are shifted relative to their literal representations and perceptual points of entry $(\mathrm{Wu}$, Waller, \& Chatterjee, 2007). That is, representation of word meaning at a neural level may not be identical to the neural processes involved in perception of its concrete referent but may be mediated instead by adjacent cortical areas. Three recent fMRI studies provide support for such an organization, all implicating the left posterolateral middle temporal cortex, just anterior to motion-sensitive area V5, in the comprehension of metaphorical extensions of motion verbs (Chen et al., 2008; Wallentin, Lund, Østergaard, Østergaard, \& Roepstorff, 2005; Wallentin, Østergaard, Lund, Østergaard, \& Roepstorff, 2005).

However, it remains to be seen whether these posterior temporal activations reflect a sensitivity to figurative senses of verbs in general or of verbs of motion in particular. The former possibility would indicate different neural resources for processing nominal versus predicate metaphors, as would be expected given their hypothesized differences in cognitive demands. The latter possibility would suggest that the perceptual qualities of the literal sense of a base term, rather than its grammatical class or the type of metaphor it is embedded within, determine the neural substrates for its metaphorical extensions. If supported, this latter possibility would also suggest that heterogeneity in the sensory-motor features associated with base terms may have contributed to the observed inconsistencies in previous neuroimaging studies of metaphor. It is also, of course, possible that both the form of the metaphor and the sensory-motor qualities of the base term interact to determine neural engagement. Thus, to distinguish the relative importance of sensory-motor grounding and metaphor type for dictating the neural basis of metaphor, it is necessary to disentangle sensory-motor qualities of base terms from the syntactic environments in which they occur (e.g., nominal vs. predicate metaphors). It is also important to control or intentionally manipulate metaphor familiarity in such designs, because readers may be more likely to draw upon sensory-motor knowledge when interpreting novel expressions (cf. Aziz-Zadeh \& Damasio, 2008).

In summary, the neural basis of metaphor remains elusive, but when coupled with rigorous stimulus control, recent conceptual frameworks motivate several potential ways to clarify the observed inconsistencies. At this point, it remains uncertain whether figurativeness, grammatical class, or sensory-motor properties are the most important determinants of neural processing of words, and how the familiarity of an expression might alter such neural engagement. We suggest that interactions between these factors are possible, probable, and worth exploring. A necessary first step for testing these neural hypotheses, and for distinguishing brain areas critical for metaphor comprehension from those more strongly recruited for any more difficult text, is the development of a large set of stimuli that is characterized along the dimensions reviewed above (frequency, concreteness, length, interpretability, familiarity, naturalness, imageability, figurativeness, processing time, novelty, metaphor type, sensory-motor qualities of base terms). If sufficiently large, such a set would enable selection of literal and metaphorical sentences such that nuisance variables can be controlled or covaried out, whereas factors of theoretical interest (e.g., novelty, metaphor type, sensory-motor grounding) can be experimentally manipulated in a categorical or a parametric fashion. The goal of the present article is to develop such a well-characterized set of literal and metaphorical stimuli and to suggest how it can be sampled to test relevant questions.

Table 1

Example Pairs of Each Sentence Type

\begin{tabular}{|c|c|c|}
\hline $\begin{array}{l}\text { Sentence } \\
\text { Type }\end{array}$ & Literal & Metaphorical \\
\hline $\mathrm{PM}$ & $\begin{array}{l}\text { The rabbits hopped in the yard. } \\
\text { The heavy box pressed against his side. }\end{array}$ & $\begin{array}{l}\text { The insults hopped on her tongue. } \\
\text { The lawyer pressed for a new trial. }\end{array}$ \\
\hline PA & $\begin{array}{l}\text { His daughter chuckled at the big glasses. } \\
\text { The hard candy rattled in the box. }\end{array}$ & $\begin{array}{l}\text { His eyes chuckled at the cute note. } \\
\text { The violent image rattled in her head. }\end{array}$ \\
\hline $\mathrm{NM}$ & $\begin{array}{l}\text { The blow was a single punch. } \\
\text { The injury was a knife stab. }\end{array}$ & $\begin{array}{l}\text { The editorial was a brass-knuckle punch. } \\
\text { The declined invitation was a stab. }\end{array}$ \\
\hline NA & $\begin{array}{l}\text { The last sip was a noisy slurp. } \\
\text { The sound was a bitter sob. }\end{array}$ & $\begin{array}{l}\text { The man's gaze was a shameless slurp. } \\
\text { Her marriage was a long sob. }\end{array}$ \\
\hline
\end{tabular}

Note-PM, predicate motion; PA, predicate auditory; NM, nominal motion; NA, nominal auditory. 


\section{METHOD}

\section{Construction of Stimuli}

An initial pool of 628 sentences of two syntactic forms - predicate or nominal-was generated (for examples, see Table 1). Predicate sentences $(n=316)$ consisted of a noun phrase and an action verb followed by a prepositional phrase. Nominal sentences $(n=312)$ consisted of two noun phrases linked by a copula (i.e., An $X$ is a $Y$ ). The predicate sentences had one or no adjective, and the nominal sentences had up to two. Half of each set expressed a literal meaning, and half expressed a metaphorical meaning. In the predicate sentences, the verb was the base term to be used figuratively in the metaphors; in the nominal sentences, the second noun was the base term in the metaphors.

To generate the predicate items, 79 verbs of visual motion and 79 verbs of sound were first selected as base terms. Next, for each verb, both a literal sentence and a metaphorical sentence were created, resulting in 158 literal-metaphor sentence pairs. In this way, in each pair, the same verb implied either a literal or a figurative interpretation, depending on its context. To generate the nominal items, 78 nouns with salient motion qualities and 78 nouns with salient sound qualities were selected as base terms. Next, for each noun, both a literal sentence and a metaphorical sentence were created, resulting in 156 literal-metaphor sentence pairs. In this way, in each pair, the same noun implied either a literal or a figurative interpretation, depending on the noun phrase and the adjectives with which it was paired. Critically, in both the predicate and the nominal sets, all metaphors involving auditory base terms were designed such that no sound was implied by the figurative interpretation of the sentence. Likewise, all metaphors involving motion base terms were designed such that no physical or fictive motion was implied by the figurative interpretation of the sentence.

To make the nominal items maximally comparable to the predicate items, the base terms in the nominal sentences were always nominalized verbs. In this way, although the syntax differed between the predicate and the nominal items, the word being used metaphorically was very similar across sentence types, ensuring the strictest test that predicate and nominal metaphors entail different cognitive processes. In order to provide a final stimulus set with the option of further maximizing similarity between predicate and nominal sentences, as many of the verbs used in the predicate sentences as possible were identical in form to the nominalized verbs used as base terms in the nominal sentences (for practical purposes, this amounted to roughly half $[n=86]$ of the base terms). A small number of predicate metaphors $(n=13)$ were modifications of those used in two previous studies (Chen et al., 2008; Torreano et al., 2005); the rest were created by the authors.

\section{Overview of Norming Studies}

This initial pool of sentences was normed both offline and online, and at both the word and sentence levels, in order to characterize its psycholinguistic properties and to highlight any problematic items (Figure 1). Before norming, three measures of length (number of characters, number of words, and number of content words) were calculated for each sentence, as well as an average frequency and concreteness score based on values for the content words of the sentence (i.e., nouns, verbs, and adjectives). In light of recent evidence that the most commonly used frequency values (Kučera \& Francis, 1967) may be outdated at this point (Brysbaert \& New, 2009), frequency values were calculated using both this traditional measure and values from SUBTLEXus, a more recent and larger corpus (Brysbaert \& New, 2009). Concreteness values were taken from the MRC Psycholinguistic Database (Coltheart, 1981) and the University of South Florida Norms (Nelson, McEvoy, \& Schreiber, 1998). For those words for which concreteness ratings were not found in either of these databases, we collected our own (Norming Study 1). Participants in this task also judged the strength of auditory and visual imagery associated with all of the base terms

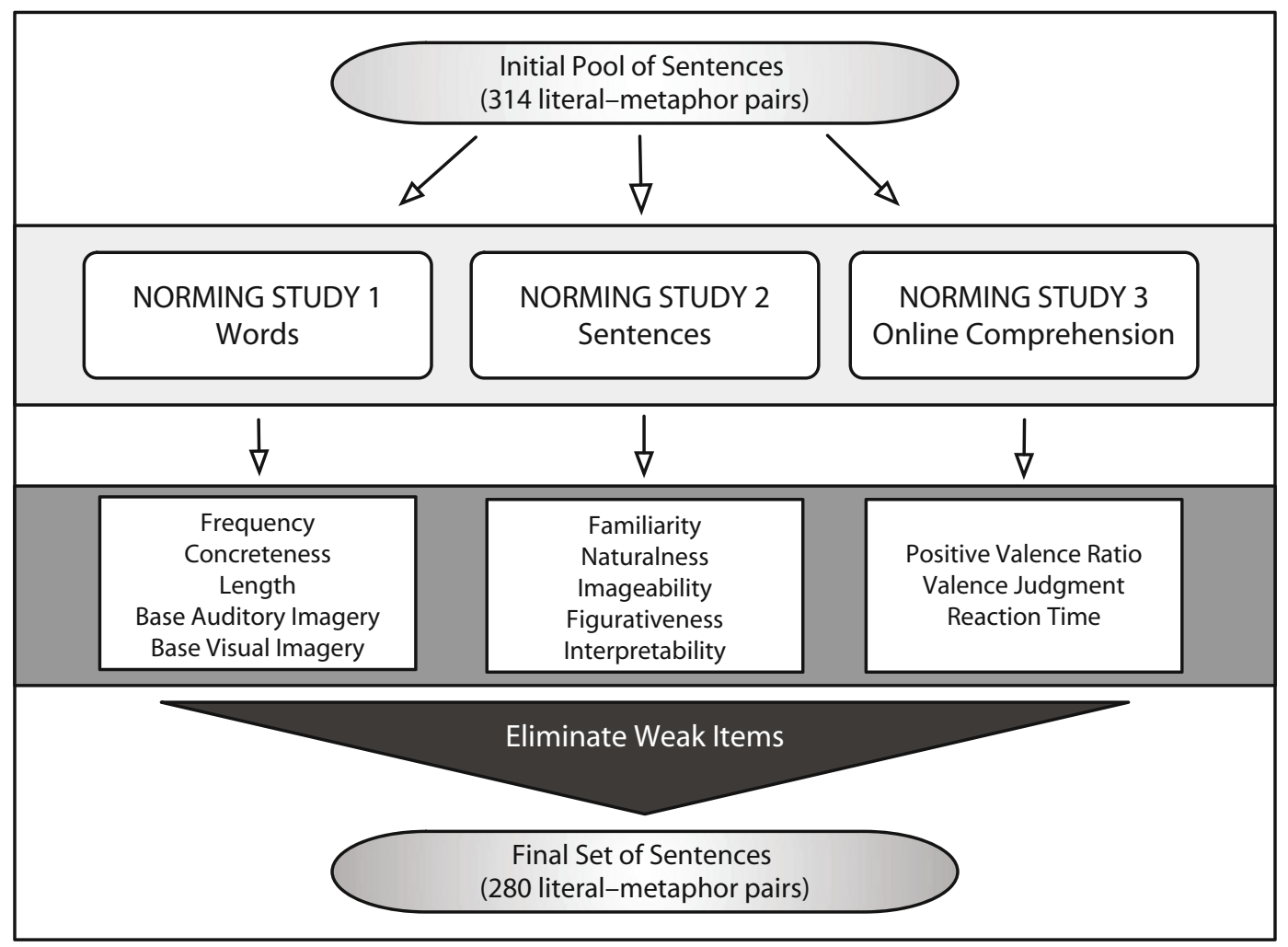

Figure 1. Overview of procedure for stimulus selection. 
in order to ensure a valid manipulation of sensory modality. A different set of individuals normed the stimuli at the sentence level, interpreting them and rating them in terms of familiarity, naturalness, imageability, and figurativeness (Norming Study 2). In addition, given the sensitivity of fMRI to reaction time, a valence judgment task was administered to a third group of individuals in order to generate an online measure of comprehension for each item (Norming Study 3). ${ }^{1}$ Together, the results of the norming studies indicated weak items to be discarded, ultimately dictating a final set of 280 literal-metaphor sentence pairs characterized by 12 lexical and sentential properties.

\section{Norming Study 1: Words}

Participants. Forty participants were recruited from the University of Pennsylvania community and were compensated $\$ 15$ or given course credit for their participation. All of the participants were proficient English speakers (all of them learned English from birth, except 1 who reported learning before the age of 5). Twenty of the participants made judgments on words from the predicate sentences (mean age $=28.6$ years, $S D=9.2 ; 5$ male; mean education $=$ 17.7 years, $S D=2.4$ ), and 20 of the participants made judgments on words from the nominal sentences (mean age $=29.6$ years, $S D=$ $10.5 ; 7$ male; mean education $=18.4$ years, $S D=3.4$ ).

Stimuli. The initial pool of sentences contained 1,860 content words, 339 of which lacked published values and thus required norming. Of these words to be normed, 155 came from the predicate sentences and 184 came from the nominal sentences (Appendix A). For auditory and visual imagery associated with base terms, all 156 verbs used in the predicate sentences were rated. Since many of these verbs were identical in form to the nominalized verbs used as base terms in the nominal sentences, only 70 of the base terms used in the nominal sentences required ratings (Appendix B).

Task. For both the predicate and the nominal items, an Excel workbook was generated with separate worksheets corresponding to the three rating tasks (concreteness, auditory imagery, visual imagery) and one line per worksheet corresponding to each item. For concreteness, the participants were instructed to rate words in terms of their accessibility to one or more of the senses using a scale from 1 (very abstract) to 7 (very concrete). For auditory imagery, the participants were instructed to rate words in terms of the speed and the "ease or difficulty with which they arouse a particular sound" using a scale from 1 (no sound) to 5 (clear sound). For visual imagery, the participants were instructed to rate words in terms of the speed and the "ease or difficulty with which they arouse a mental picture or visual image" using a scale from 1 (no image) to 5 (clear image). In all cases, instructions were coupled with several examples and explanations. ${ }^{2}$ The participants worked at their own pace and made these judgments as part of a larger word-norming task. The task required approximately $40 \mathrm{~min}$ to complete.

Data analysis. For all words, ratings were averaged over the 20 participants for each of the three judgments. The 339 new concreteness values supplemented the previously published values for the other 1,521 content words in the stimulus set. These individual concreteness ratings were then used to determine an average concreteness value for each of the 628 candidate sentences (i.e., the sum of the concreteness values associated with each content word in any particular sentence divided by the number of content words in that sentence). The imagery ratings of the base terms indicated six problematic base terms: Four base terms used in the auditory conditions (blubber, serenade, splash, and yawn) elicited stronger visual than auditory imagery, and two used in the motion conditions (wind and stomp) elicited stronger auditory than visual imagery.

\section{Norming Study 2: Sentences}

Participants. Eighty participants were recruited from the University of Pennsylvania community and were compensated $\$ 25$ or given course credit for their participation. All of the participants were proficient English speakers (all of them learned English from birth, except again for 1 person who reported learning before the age of 5), and none had participated in Norming Study 1. Forty participants made judgments on the predicate sentences (mean age $=$ 20.8 years, $S D=2.5 ; 12$ male; mean education $=14.7$ years, $S D=$ 1.6), and 40 participants made judgments on the nominal sentences (mean age $=20.4$ years, $S D=2.9 ; 11$ male; mean education $=$ 14.6 years; $S D=1.8$ ).

Stimuli. All 628 candidate sentences were assessed.

Task. The sets of predicate $(n=316)$ and nominal $(n=312)$ items were randomly divided in half, and for each of these subsets an Excel workbook was generated with separate worksheets corresponding to the five norming tasks (familiarity, naturalness, imageability, figurativeness, interpretation) and one line per worksheet corresponding to each item. In this way, the participants in the predicate condition saw one of two possible lists of predicate stimuli (both literal and metaphorical), and the participants in the nominal condition saw one of two possible lists of nominal stimuli (both literal and metaphorical), with the ratings for each sentence based on the responses of 20 individuals.

For the familiarity task, the participants were instructed to rate their frequency of experience with the sentence and its meaning, using a scale from 1 (very unfamiliar) to 7 (very familiar). For the naturalness task, the participants were instructed to rate each sentence for how "natural and normal" it seemed, using a scale from 1 (very unnatural) to 7 (very natural). For the imageability task, the participants were instructed to rate "how quickly and easily each sentence brought a visual image to mind," using a scale from 1 (no image) to 7 (clear, immediate image). For the figurativeness task, the participants were instructed to rate how literal an interpretation each sentence suggested, using a scale from 1 (very literal) to 7 (very figurative). For the interpretation task, participants were instructed to write the meaning of each sentence using their own words. Familiarity, naturalness, imageability, and figurativeness ratings were collected for both the literal and the metaphorical sentences. Given the difficulty of restating a concrete, literal sentence in novel words and the absence of any theoretical relevance for such descriptions, interpretations were only collected for the metaphors. The task required approximately $90 \mathrm{~min}$ to complete.

Data analysis. To determine interpretability, several steps were necessary for each item and for each participant. First, for each metaphor, three of the authors independently judged the number of interpretations that reflected a plausible, figurative construal of the sentence. For some sentences, all interpretations reflected a single meaning; for many others, responses indicated multiple or overlapping meanings. For instance, despite being rated as fairly familiar, the metaphor The day's events were a whir received various responses. Some interpreted the metaphorical sense of whir to mean that the day was busy or passed quickly (e.g., There were a lot of events that happened in the day, and they went quickly), whereas others interpreted the base term to mean that the day's events were hard to remember (e.g., Looking back, what happened today is fuzzy and unclear). Still others interpreted the sentence to mean both (e.g., The day's events went by so quickly that they seemed blurred in retrospect). This variability in response is unlikely to indicate that the item is difficult to understand; without context, all of these interpretations are reasonable. Both for this reason and given the subjectivity in determining where one meaning ends and another begins, rather than tallying the incidence of the most common interpretation, any plausible figurative interpretation was taken to indicate that the metaphor had been understood. In contrast, blank, nonsensical, literal, or uninformative (e.g., Just what it says) interpretations were not taken to indicate metaphoric comprehension.

All three judges were in full agreement (all three agreed that an interpretation was plausible, or all three agreed that an interpretation was not plausible) on $91.0 \%$ of the responses across the four lists $($ range $=90.2 \%-92.0 \%$ ). Similarly, at least two out of the three judges agreed that an interpretation was plausible for $91.4 \%$ of the responses across the four lists (range $=89.0 \%-94.2 \%$ ).

Finally, an interpretability score for each participant was calculated by dividing the number of their interpretations that were 
deemed plausible by at least two judges by the total number of items assessed by that participant (the number of plausible interpretations divided by the number of all possible interpretations). This assessment revealed poor comprehension by 4 participants ( $>30 \%$ of their interpretations were not considered plausible), so their data were excluded from subsequent analyses. To generate familiarity, naturalness, imageability, and figurativeness ratings for each item, averages were derived from the responses made by the remaining participants. To generate an interpretability score for each item, the number of interpretations deemed plausible by at least two judges was divided by the total number of interpretations for that item. The results indicated 18 metaphors that failed to reach our minimum desired comprehensibility criterion of $70 \%$ plausible interpretations.

\section{Norming Study 3: Online Comprehension}

Participants. Forty participants were recruited from the University of Pennsylvania community and were compensated $\$ 15$ or given course credit for their participation. All of the participants were native English speakers. Twenty participants (mean age $=23.9$ years, $S D=3.4 ; 7$ male) made judgments on the predicate sentences, and 20 participants (mean age $=19.1$ years, $S D=1.1 ; 13$ male) made judgments on the nominal sentences. None had participated in Norming Studies 1 or 2.

Stimuli. In the predicate condition, all 158 candidate predicate metaphors and their literal counterparts were assessed. In the nominal condition, all 156 candidate nominal metaphors and their literal counterparts were assessed.

Task. The sentences were presented centrally in black 18-point font on a white background, using E-Prime 1.1 software on a Dell Inspiron laptop. The sentences were displayed for 3,000 msec and separated by a $1,000-\mathrm{msec}$ intertrial interval. The participants were instructed to read each sentence and then judge its emotional valence, using the " $f$ " key to indicate a positive valence and the " $\mathrm{j}$ " key to indicate a neutral or negative valence. They were informed that there was no right or wrong answer and were encouraged to respond as quickly as possible. Twelve practice trials preceded four blocks of experimental trials. Each participant received a different random order of items and saw each sentence only once. The task required approximately $20 \mathrm{~min}$ to complete.

Data analysis. For every sentence, reaction times were averaged across participants and the proportion of positive valence judgments was calculated. Because of computer errors, these values were not available for 18 literal-metaphor pairs in the predicate condition.

\section{RESULTS}

The results of the norming studies were used to eliminate problematic stimuli from the initial pool. The imagery ratings from Norming Study 1 and the interpretability scores from Norming Study 2 indicated 24 literal-metaphor sentence pairs to be discarded, resulting in $73,75,71$, and 70 remaining possible sentence pairs in the predicate-auditory, predicate-motion, nominal-auditory, and nominal-motion conditions, respectively. In order to generate a final stimulus set with equal numbers of items in each condition (i.e., 70 metaphors and 70 matched literal sentences), items in the predicate-auditory, predicate-motion, and nominalauditory conditions with the lowest interpretability values were also discarded. In this final set, the overlap in base terms between the predicate and the nominal sentences remained roughly half (67 out of 140). The lexical and sentential characteristics of the final set of 560 sentences are summarized in Table 2, and an example set of items can be found in Appendix C (see the supplemental materials for the full set of items and their normative values).

We intentionally did not calculate statistical differences between sentence types, because our aim is not for the stimulus set to be used in its entirety but, rather, for it to be sampled in ways that control for condition differences or for the normative data to be used to covary out the influence of nuisance variables. Nonetheless, the overall means indicate some areas in which such control is likely to be necessary. Although the literal and metaphorical sentences had comparable length, frequency, and concreteness values, unsurprisingly, the literal sentences were judged to be less figurative and more familiar, natural, and imageable than metaphorical sentences in both the predicate and the nominal sets. Also, despite the inclusion of additional adjectives, the nominal sentences tended to be shorter than the predicate sentences on all length measures. Importantly, our online comprehension measure suggested no major differences in the time required to make semantic judgments

Table 2

Summary of Final Stimulus Characteristics by Sentence Type

\begin{tabular}{|c|c|c|c|c|c|c|c|c|c|c|c|c|c|c|c|c|}
\hline \multirow[b]{3}{*}{ Measure } & \multicolumn{8}{|c|}{ Literal } & \multicolumn{8}{|c|}{ Metaphorical } \\
\hline & \multicolumn{2}{|c|}{ PA } & \multicolumn{2}{|c|}{ PM } & \multicolumn{2}{|c|}{ NA } & \multicolumn{2}{|c|}{ NM } & \multicolumn{2}{|c|}{ PA } & \multicolumn{2}{|c|}{ PM } & \multicolumn{2}{|c|}{ NA } & \multicolumn{2}{|c|}{ NM } \\
\hline & $M$ & $S D$ & $M$ & $S D$ & $M$ & $S D$ & $M$ & $S D$ & $M$ & $S D$ & $M$ & $S D$ & $M$ & $S D$ & $M$ & $S D$ \\
\hline Base auditory imagery & 3.96 & 0.5 & 1.46 & 0.4 & 4.03 & 0.5 & 1.69 & 0.6 & 3.96 & 0.5 & 1.46 & 0.4 & 4.03 & 0.5 & 1.69 & 0.6 \\
\hline Base visual imagery & 2.82 & 0.5 & 3.52 & 0.7 & 2.72 & 0.6 & 3.63 & 0.7 & 2.82 & 0.5 & 3.52 & 0.7 & 2.72 & 0.6 & 3.63 & 0.7 \\
\hline Concreteness & 510 & 48 & 502 & 50 & 434 & 65 & 440 & 55 & 492 & 155 & 477 & 57 & 434 & 65 & 422 & 61 \\
\hline Frequency ${ }^{a}$ & 83 & 108 & 85 & 93 & 83 & 142 & 73 & 88 & 92 & 108 & 100 & 111 & 60 & 78 & 78 & 91 \\
\hline Frequencyb & 103 & 118 & 82 & 123 & 92 & 140 & 86 & 173 & 70 & 93 & 113 & 169 & 72 & 137 & 78 & 94 \\
\hline No. of characters & 36.5 & 5.7 & 37.4 & 5.2 & 30.8 & 4.1 & 31.1 & 3.9 & 37.3 & 5.2 & 38.8 & 4.8 & 32.1 & 4.4 & 31.9 & 3.8 \\
\hline No. of words & 6.5 & 0.8 & 6.5 & 0.6 & 5.9 & 0.4 & 6.1 & 0.4 & 6.6 & 0.8 & 6.5 & 0.7 & 6.0 & 0.5 & 6.1 & 0.4 \\
\hline No. of content words & 3.6 & 0.6 & 3.6 & 0.5 & 3.0 & 0.4 & 3.1 & 0.4 & 3.6 & 0.7 & 3.6 & 0.5 & 3.0 & 0.4 & 3.1 & 0.4 \\
\hline Interpretability & & & & & & & & & 0.95 & 0.06 & 0.96 & 0.06 & 0.93 & 0.08 & 0.92 & 0.09 \\
\hline Familiarity & 5.81 & 0.82 & 5.51 & 0.9 & 5.30 & 0.8 & 5.32 & 0.9 & 2.84 & 1.1 & 4.11 & 1.4 & 3.81 & 1.2 & 4.13 & 1.2 \\
\hline Naturalness & 5.88 & 0.84 & 5.66 & 0.9 & 5.78 & 0.8 & 5.76 & 0.8 & 3.00 & 1.0 & 4.15 & 1.3 & 4.09 & 1.2 & 4.56 & 1.2 \\
\hline Imageability & 6.07 & 0.72 & 6.15 & 0.7 & 5.12 & 0.8 & 5.84 & 0.8 & 3.14 & 0.8 & 3.45 & 1.3 & 3.90 & 0.9 & 4.06 & 0.8 \\
\hline Figurativeness & 1.50 & 0.56 & 1.69 & 0.7 & 2.27 & 0.7 & 2.16 & 0.8 & 6.15 & 0.6 & 5.33 & 1.0 & 5.31 & 0.7 & 5.42 & 0.8 \\
\hline Valence RT & 1,455 & 220 & 1,459 & 185 & 1,388 & 189 & 1,485 & 220 & 1,528 & 185 & 1,591 & 197 & 1,491 & 256 & 1,485 & 201 \\
\hline Valence positive ratio & 0.19 & 0.26 & 0.21 & 0.24 & 0.17 & 0.26 & 0.29 & 0.29 & 0.18 & 0.27 & 0.25 & 0.28 & 0.27 & 0.32 & 0.28 & 0.32 \\
\hline
\end{tabular}

Note-PA, predicate auditory; PM, predicate motion; NA, nominal auditory; NM, nominal motion; Frequencya , values from Kučera and Francis (1967); Frequencyb, SUBTL ${ }_{\mathrm{WF}}$ values from Brysbaert and New (2009); RT, reaction time (in milliseconds). 
about the different classes of metaphorical and literal sentences, and interpretability was consistently very high across all metaphor types. The only difference to emerge at this group level regarded predicate metaphors with verbs of sound, which were overall judged to be more figurative and less familiar, natural, and imageable than the other three metaphor types. As was intended, the base terms consisting of verbs of motion or nominalized verbs of motion were rated as having more salient visual imagery and less salient auditory imagery than the base terms consisting of verbs of sound or nominalized verbs of sound (and vice versa).

To further explore relationships between sentence-level factors of theoretical interest, the five normative values collected for each sentence (familiarity, naturalness, imageability, figurativeness, and interpretability) were correlated with each other separately for the predicate and nominal metaphors (Table 3 ). The results indicated several expected relationships. In both the predicate and the nominal metaphors, familiarity and naturalness were highly correlated, indicating that these constructs are either conceptually indistinguishable or at least practically difficult to disentangle. We suggest then that there is little utility for future researchers to norm on both measures. Both metaphor sets also indicated that sentences rated higher in familiarity and naturalness tend to evoke greater visual imagery, are perceived as less figurative, and are more easily understood. Yet, these patterns are not sufficiently strong that they cannot be orthogonalized with careful item selection. Most important with respect to future use, it is possible with these stimuli to disentangle ease of comprehension from metaphoricity. Despite the relative novelty of the metaphors in this stimulus set, in neither the predicate nor the nominal metaphor sets were the correlations between interpretability and figurativeness significant.

By and large, the metaphor sets showed very similar relationships between the sentence-level factors. The only clear difference to emerge concerned imageability. Separate correlational analyses by modality and metaphor type (Table 4) indicated that this difference between metaphor types related to the modality of their base terms. No relationship between figurativeness and imageability was observed in nominal-auditory, nominal-motion, or predicate-

Table 3

Correlation Coefficients Between Sentence Scales, Collapsed Across Modality

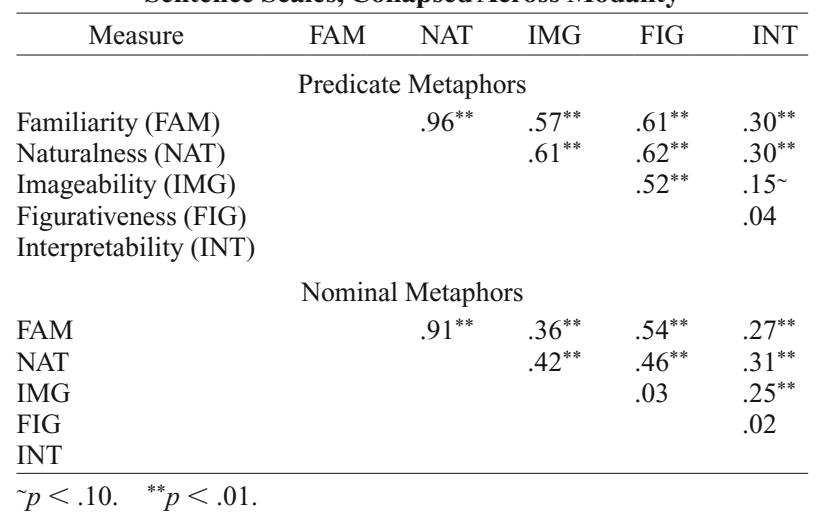

Table 4

Correlation Coefficients Between Sentence Scales As a Function of Modality and Metaphor Type

\begin{tabular}{|c|c|c|c|c|c|}
\hline Measure & FAM & NAT & IMG & FIG & INT \\
\hline \multicolumn{6}{|c|}{ Predicate Auditory Metaphors } \\
\hline Familiarity (FAM) & & $.93^{* *}$ & $.33^{* *}$ & $.55^{* *}$ & $.36^{* *}$ \\
\hline Naturalness (NAT) & & & $.43^{* *}$ & $.53^{* *}$ & $.36^{* *}$ \\
\hline Imageability (IMG) & & & & .14 & $.21^{\sim}$ \\
\hline Figurativeness (FIG) & & & & & .01 \\
\hline
\end{tabular}

Interpretability (INT)

\begin{tabular}{lllll}
\multicolumn{5}{c}{ Nominal Auditory Metaphors } \\
FAM & $.89^{* *}$ & $.42^{* *}$ & $.57^{* *}$ & $.35^{* *}$ \\
NAT & & $.40^{* *}$ & $.56^{* *}$ & $.40^{* *}$ \\
IMG & & & .11 & $.27^{*}$ \\
FIG & & & & $.21^{\sim}$
\end{tabular}

INT

\begin{tabular}{lcccc}
\multicolumn{5}{c}{ Predicate Motion Metaphors } \\
FAM & $.97^{* *}$ & $.69^{* *}$ & $.50^{* *}$ & $.24^{*}$ \\
NAT & & $.71^{* *}$ & $.53^{* *}$ & $.25^{*}$ \\
IMG & & & $.66^{* *}$ & .11 \\
FIG & & & & .01
\end{tabular}

INT

Nominal Motion Metaphors

$\begin{array}{lllll}\text { FAM } & .92^{* *} & .28^{*} & .55^{* *} & .22^{\sim} \\ \text { NAT } & & .41^{* *} & .42^{* *} & .26^{*} \\ \text { IMG } & & & .13 & .24^{*} \\ \text { FIG } & & & & .13\end{array}$

INT

${ }_{\sim p} p .10 . \quad{ }^{* *} p<.01 . \quad{ }^{*} p<.05$.

auditory items. In contrast, for predicate metaphors with motion base terms, the more figurative a metaphor was judged, the less it evoked a visual image.

\section{DISCUSSION}

We have developed a large set of metaphorical and literal sentences that - although they are certainly unable to address all questions of interest - have several advantages over existing sources of stimuli that might be used in cognitive neuroscience studies of metaphor. To our knowledge, this is one of the largest available stimulus sets (see also Katz, Paivio, Marschark, \& Clark, 1988; Torreano et al., 2005), and it is characterized on more dimensions than in most extant sets. In addition, we have included more than one type of metaphor, both in terms of syntactic form and sensory modality, and our metaphors are relatively novel. Our metaphors also have higher interpretability than is generally reported, especially for novel metaphors, and are matched on an item-by-item basis with a sentence using the figurative base term in a literal sense. With the exception of interpretability, these literal sentences have been normed on all the same dimensions as the metaphors, making them optimal control items in cognitive neuroscience studies of metaphor (as well as suitable sentences for studies of literal language processing).

Most importantly, to our knowledge, this is the only set of stimuli specifically designed to address hypotheses relevant to cognitive neuroscience. If widely adopted, their use could facilitate cross-study comparison and, critically, avoid potential lexical and sentential confounds that have 
made integrating results of previous studies difficult. Despite some of the correlations observed, the stimulus set allows disentangling typically correlated characteristics by selectively sampling it in either of two ways: splitting by a dimension of interest while balancing on nuisance variables or using them as covariates, or parametrically varying a dimension of interest while balancing on nuisance variables or using them as covariates. For instance, the first approach could be used in order to test proposed differences in the cognitive processing entailed by different metaphor types. To do so, one could consider only items of a single base term modality (motion or sound), divide that modality by metaphor type (nominal vs. predicate), and then selectively remove items in such a way that nominal and predicate metaphors and their literal counterparts closely match on lexical and sentential properties. This sorting approach could also be used to test whether the sensory-motor features of the base term determine the neural substrates of its literal and metaphoric senses. In this case, one could consider only metaphors of a single type, divide them instead by modality, then selectively remove items in such a way that auditory and motion metaphors, and their literal counterparts, closely match on lexical and sentential properties. Careful sampling of the stimuli also enables the parametric manipulation of novelty within either of the previous examples of categorical sampling. Alternatively, novelty could be addressed by restricting initial selection of items to items of high or low familiarity or by using familiarity ratings as a covariate of noninterest. By combining sampling approaches in this way, interactions between novelty and metaphor type or modality can be considered.

These are possibilities that we are currently pursuing in our lab, but we can imagine other ways in which these stimuli could be extended, either by the addition of items or by behavioral norming with different tasks. For example, the notion of novelty requires unpacking. The novelty of these stimuli is currently described in terms of their familiarity at the level of the whole sentence, but they could also be characterized by several other closely related concepts - conventionality, aptness, and salience. Although often used interchangeably with familiarity, more precisely, conventionality refers to how strongly a figurative meaning is associated with a specific base term (Gentner \& Wolff, 1997). Aptness loosely refers to the goodness of a metaphor or, more specifically, the degree to which the base expresses important features of the target (Chiappe, Kennedy, \& Chiappe, 2003). Recent behavioral studies demonstrate that aptness may be driving effects otherwise attributed to conventionality (Chiappe et al., 2003; Jones \& Estes, 2006). Salience is a composite construct referring to an expression's most prominent meaning, as determined by familiarity, conventionality, context, and frequency (Giora, 1999). Because familiarity, conventionality, aptness, and salience are often highly correlated dimensions, the degree to which they reflect cognitively and neurally relevant distinctions remains an open question. Although conventionality and familiarity are constructs easily applied to other classes of metaphor, as it is strictly defined, aptness is less easily extended to predicate metaphors. This stimulus set presents a chal- lenge, as well as an opportunity to develop the conceptualization of novelty and a precise model for how these factors conspire to affect comprehension.

More pressing, neuroimaging experiments cannot distinguish areas necessary for successful performance in a metaphor task from those areas that are simply involved in the task; to make such inferences, fMRI and PET research is best complemented by studies involving brain-injured individuals. However, the patient literature with respect to metaphor is quite limited. In addition to the already highlighted methodological weaknesses of some studies (Schmidt et al., 2010), one obvious shortcoming is the narrowness of the sampled metaphor probes. In most studies, only the metaphoric extension of adjectives have been considered (Brownell et al., 1984; Brownell et al., 1990; Gagnon, Goulet, Giroux, \& Joanette, 2003; Giora et al., 2000; Mackenzie, Begg, Lees, \& Brady, 1999; Tompkins, 1990; Winner \& Gardner, 1977; Zaidel, Kasher, Soroker, \& Batori, 2002), or the potentially quite different domain of idioms (Cacciari et al., 2006; Kempler et al., 1999; Papagno \& Caporali, 2007; Papagno \& Genoni, 2004; Papagno, Tabossi, Colombo, \& Zampetti, 2004; Rinaldi, Marangolo, \& Baldassarri, 2004; Tompkins, Boada, \& McGarry, 1992; Van Lancker \& Kempler, 1987) have been considered. At this point, neither nominal nor predicate metaphors have been considered in any patient study. Neither has comprehension of novel metaphors.

As these various suggested lines of research illustrate, these stimuli are designed to address current questions about the neural basis of metaphor comprehension. They are, of course, not without their limitations. For instance, despite the inclusion of additional adjectives in the nominal sentences, these items are generally still shorter than the predicate items. Similarly, although literal sentences were made as similar to the metaphors as possible, they were still rated as more imageable and familiar. Circumventing these differences, however, would have created more problematic issues. For example, adding even more adjectives to the nominals would equalize length with that of the predicates, but it would also mean that the nominals might require greater semantic processing in order to integrate the additional semantic information. Using more abstract words in literal sentences would likely equate imageability with metaphors, but at the expense of differences in their concreteness values. Making literal sentences less familiar would, on first pass, seem desirable, but doing so would require such unlikely combinations of words (e.g., He is sitting deep in the bubbles; Kempler et al., 1999) that we feared that they might seem metaphorical when paired with our novel metaphors.

In addition, we constrained the stimulus set in certain ways. We have provided normative data for only one online task: a valence judgment. We believe this to be an appropriate index for ensuring comparability between conditions in terms of semantic processing time, but future researchers may want to add others. We have also avoided familiar metaphors, limiting the set to relatively novel expressions instead, since they are scarce in the literature.

Careful stimulus selection and the use of covariates can address some of these limitations. For others, we hope to 
have provided a protocol for generating similar stimuli in other languages or to augment the current set as theories of metaphors evolve. Although most of the measures that we have included consist of straightforward ratings or easily acquired psycholinguistic values, we have taken a laborious approach to assessing interpretability that has important benefits. Ratings of comprehensibility using an ordinal scale are a frequently employed and easy to acquire measure (e.g., rate how easy this statement is to understand using a scale from 1 [not at all] to 7 [very easy]) but are coarse in what they can indicate. One cannot know whether the interpretation that any given reader generated when ranking a stimulus was actually reasonable or even metaphorical, nor does one have any sense of whether the particular interpretation assigned to the item varied between individuals. These shortcomings are especially problematic when one is interested in how anything but the most conventional of metaphors is understood. In everyday language, metaphors are rarely encountered out of context. Foregrounding information likely strongly biases the salience of a figurative interpretation (Giora, 1999). However, as our interpretation task demonstrated, an isolated metaphor of even fairly high familiarity may evoke several different senses. For this reason, it seems sensible to operationalize the interpretability of a metaphor in terms of the plausibility of interpretations, regardless of consensus or lack thereof. Using more than one rater of plausibility is also preferable, given the subjective nature of interpretation, especially for less familiar metaphors.

\section{CONCLUSION}

Given metaphor's likely standing as a hallmark of human intelligence, characterizing its neural basis is a goal with broad interest. Nonetheless, the accumulated evidence does not fall out coherently. We suggest that cognitive neuroscience research on metaphor has been hampered by a lack of adequately controlled stimuli and by the fact that stimulus designs have not always kept apace with emergent theoretical frameworks or have addressed them too narrowly. We aim to fill this gap with this large, extensively normed, flexible, and theoretically motivated set of stimuli.

\section{AUTHOR NOTE}

This research was supported by National Institutes of Health Grants R01-HD-050199-01A2 and R01-DC-008779-01 awarded to A.C. We thank Bianca Bromberger and Page Widick for their help collecting and organizing the data. Correspondence concerning this article should be addressed to E. R. Cardillo, Department of Neurology, University of Pennsylvania, 3 West Gates, 3400 Spruce Street, Philadelphia, PA 19104 (e-mail: eica@mail.med.upenn.edu).

\section{REFERENCES}

Amorapanth, P. X., Widick, P., \& Chatterjee, A. (2009). The neural basis of spatial relations. Journal of Cognitive Neuroscience, $\mathbf{2 2}$, 1739-1753.

Arzouan, Y., Goldstein, A., \& Faust, M. (2007). Dynamics of hemispheric activity during metaphor comprehension: Electrophysiological measures. NeuroImage, 36, 222-231.
Aziz-Zadeh, L., \& Damasio, A. (2008). Embodied semantics for actions: Findings from functional brain imaging. Journal of Physiology, Paris, 102, 35-39.

Balota, D. A., YaP, M. J., \& Cortese, M. J. (2006). Visual word recognition: The journey from features to meaning (A travel update). In M. Traxler \& M. A. Gernsbacher (Eds.), Handbook of psycholinguistics (pp. 285-375). New York: Elsevier.

Binder, J. R., Medler, D. A., Desai, R., Conant, L. L., \& LiebenTHAL, E. (2005). Some neurophysiological constraints on models of word naming. NeuroImage, 27, 677-693.

Binder, J. R., Westbury, C. F., McKiernan, K. A., Possing, E. T., \& MedLeR, D. A. (2005). Distinct brain systems for processing concrete and abstract concepts. Journal of Cognitive Neuroscience, $\mathbf{1 7}$ 905-917.

Boroditsky, L. (2000). Metaphoric structuring: Understanding time through spatial metaphors. Cognition, 75, 1-28.

Bottini, G., Corcoran, R., Sterzi, R., Paulesu, E., Schenone, P., SCARPA, P., ET AL. (1994). The role of the right hemisphere in the interpretation of figurative aspects of language: A positron emission tomography activation study. Brain, 117, 1241-1253.

BowdLe, B. F., \& GentNer, D. (2005). The career of metaphor. Psychological Review, 112, 193-216.

Brownell, H. H., Potter, H. H., Michelow, D., \& Gardner, H. (1984). Sensitivity to lexical denotation and connotation in braindamaged patients: A double dissociation. Brain \& Language, 22, 253-265.

Brownell, H. H., Simpson, T. L., Bihrle, A. M., Potter, H. H., \& GARDNER, H. (1990). Appreciation of metaphoric alternative word meanings by left and right brain-damaged patients. Neuropsychologia, 28, 375-383.

Brysbaert, M., \& New, B. (2009). Moving beyond Kučera and Francis: A critical evaluation of current word frequency norms and the introduction of a new and improved word frequency measure for American English. Behavior Research Methods, 41, 977-990.

Cacciari, C., Reati, F., Colombo, M. R., Padovani, R., Rizzo, S. \& Papagno, C. (2006). The comprehension of ambiguous idioms in aphasic patients. Neuropsychologia, 44, 1305-1314.

Cardillo, E. R., Aydelott, J., Matthews, P. M., \& Devlin, J. T. (2004). Left inferior prefrontal cortex activity reflects inhibitory rather than facilitatory priming. Journal of Cognitive Neuroscience, 16, $1552-1561$.

Chatterjee, A. (2008). The neural organization of spatial thought and language. Seminars in Speech \& Language, 29, 226-238.

Chen, E., Widick, P., \& Chatterjee, A. (2008). Functional-anatomical organization of predicate metaphor processing. Brain \& Language, 107, 194-202.

Chiappe, D. L., Kennedy, J. M., \& Chiappe, P. (2003). Aptness is more important than comprehensibility in preference for metaphors and similes. Poetics, 31, 51-68.

Coltheart, M. (1981). The MRC Psycholinguistic Database. Quarterly Journal of Experimental Psychology, 33, 497-505.

Constable, R. T., Pugh, K. R., Berroya, E., Mencl, W. E., WesterVeld, M., Ni, W., \& Shankweiler, D. (2004). Sentence complexity and input modality effects in sentence comprehension: An fMRI study. NeuroImage, 22, 11-21.

FiebaCH, C. J., \& FRIEDERICI, A. D. (2003). Processing concrete words: fMRI evidence against a specific right-hemisphere involvement. Neuropsychologia, 42, 62-70.

Friederici, A. D., Fiebach, C. J., Schlesewsky, M., Bornkessel, I. D., \& von Cramon, D. Y. (2006). Processing linguistic complexity and grammaticality in the left frontal cortex. Cerebral Cortex, 16, 1709-1717.

Gagnon, L., Goulet, P., Giroux, F., \& Joanette, Y. (2003). Processing of metaphoric and non-metaphoric alternative meanings of words after right- and left-hemispheric lesion. Brain \& Language, 87, 217-226.

GentNer, D. (2003). Why we're so smart. In D. Gentner \& S. GoldinMeadow (Eds.), Language in mind: Advances in the study of language and thought (pp. 195-235). Cambridge, MA: MIT Press.

Gentner, D., Bowdle, B. F., WolfF, P., \& Boronat, C. (2001). Metaphor is like analogy. In D. Gentner, K. J. Holyoak, \& B. N. Kokinov (Eds.), The analogical mind: Perspectives from cognitive science (pp. 199-253). Cambridge, MA: MIT Press. 
Gentner, D., \& WolfF, P. (1997). Alignment in the processing of metaphor. Journal of Memory \& Language, 37, 331-355.

GiBBs, R. W. (2006). Metaphor interpretation as embodied simulation. Mind \& Language, 21, 434-458.

Gilhooly, K. L., \& LogIE, R. H. (1980). Age of acquisition, imagery, concreteness, familiarity, and ambiguity measures for 1,944 words. Behavioural Research Methods \& Instrumentation, 12, 395-427.

GIORA, R. (1999). On the priority of salient meanings: Studies of literal and figurative language. Journal of Pragmatics, 31, 919-929.

Giora, R., ZAidel, E., SOROKER, N., BATORI, G., \& KASHer, A. (2000). Differential effects of right- and left-hemisphere damage on understanding sarcasm and metaphor. Metaphor \& Symbol, 15, 63-83.

GLUCKSBERG, S. (2003). The psycholinguistics of metaphor. Trends in Cognitive Sciences, 7, 92-96.

Grice, H. P. (1975). Logic and conversation. In P. Cole \& J. L. Morgan (Eds.), Syntax and semantics: Speech acts (Vol. 3, pp. 41-58). New York: Academic Press.

Hauk, O., Davis, M. H., \& Pulvermüller, F. (2008). Modulation of brain activity by multiple lexical and word form variables in visual word recognition: A parametric fMRI study. Neurolmage, 42, 11851195.

Ishai, A., Ungerleider, L. G., Martin, A., \& Haxby, J. V. (2000). The representation of objects in the human occipital and temporal cortex. Journal of Cognitive Neuroscience, 12(Suppl. 2), 35-51.

Ishai, A., Ungerleider, L. G., Martin, A., Schouten, J. L., \& HaXby, J. V. (1999). Distributed representation of objects in the human ventral visual pathway. Proceedings of the National Academy of Sciences, 96, 9379-9384.

JoNES, L. L., \& Estes, Z. (2006). Roosters, robins, and alarm clocks: Aptness and conventionality in metaphor comprehension. Journal of Memory \& Language, 55, 18-32.

Just, M. A., Carpenter, P. A., Keller, T. A., Eddy, W. F., \& ThulBORN, K. R. (1996). Brain activation modulated by sentence comprehension. Science, 274, 114-116.

Just, M. A., Newman, S. D., Keller, T. A., McEleney, A., \& CarPENTER, P. A. (2004). Imagery in sentence comprehension: An fMRI study. NeuroImage, 21, 112-124.

Kable, J. W., \& Chatterjee, A. (2006). Specificity of action representations in the lateral occipitotemporal cortex. Journal of Cognitive Neuroscience, 18, 1498-1517.

Kable, J. W., Kan, I. P., Wilson, A., Thompson-Schill, S. L., \& ChatTERJEE, A. (2005). Conceptual representations of action in the lateral temporal cortex. Journal of Cognitive Neuroscience, 17, 1855-1870.

Katz, A. N., Paivio, A., Marschark, M., \& Clark, J. M. (1988). Norms for 204 literary and 260 nonliterary metaphors on 10 psychological dimensions. Metaphor \& Symbolic Activity, 3, 191-214.

Keller, T. A., Carpenter, P. A., \& Just, M. A. (2001). The neural bases of sentence comprehension: A fMRI examination of syntactic and lexical processing. Cerebral Cortex, 11, 223-237.

Kemmerer, D. (2006). The semantics of space: Integrating linguistic typology and cognitive neuroscience. Neuropsychologia, 44, 1607-1621.

Kempler, D., Van Lancker, D., Marchman, V., \& Bates, E. (1999). Idiom comprehension in children and adults with unilateral brain damage. Developmental Neuropsychology, 15, 327-349.

Kircher, T. T. J., Leube, D. T., Erb, M., Grodd, W., \& RapP, A. M. (2007). Neural correlates of metaphor processing in schizophrenia. NeuroImage, 34, 281-289.

Kosslyn, S. M., Maljkovic, V., Hamilton, S. E., Horowitz, G., \& Thompson, W. L. (1995). Two types of image generation: Evidence for left and right hemisphere processes. Neuropsychologia, 33, 14851510

KuČERA, H., \& FranCIS, W. N. (1967). Computational analysis of presentday American English. Providence, RI: Brown University Press.

Kuperberg, G. R., Holcomb, P. J., Sitnikova, T., Greve, D., Dale, A. M., \& CAPLAN, D. (2003). Distinct patterns of neural modulation during the processing of conceptual and syntactic anomalies. Journal of Cognitive Neuroscience, 15, 272-293.

Kutas, M. (2006). One lesson learned: Frame language processingliteral and figurative - as a human brain function. Metaphor \& Symbol, 21, 285-325.

Lakoff, G., \& Johnson, M. (1980). Metaphors we live by. Chicago: University of Chicago Press.

LeE, S. S., \& DAPRETTO, M. (2006). Metaphorical vs. literal word mean- ings: fMRI evidence against a selective role of the right hemisphere. NeuroImage, 29, 536-544.

Mackenzie, C., BegG, T., Lees, K. R., \& Brady, M. (1999). The communication effects of right brain damage on the very old and the not so old. Journal of Neurolinguistics, 12, 79-93.

Martin, A., Ungerleider, L. G., \& HaXby, J. V. (2000). Category specificity and the brain: The sensory/motor model of semantic representations of objects. In M. S. Gazzaniga (Ed.), The new cognitive neurosciences (2nd ed., pp. 1023-1036). Cambridge, MA: MIT Press.

Mashal, N., Faust, M., \& Hendler, T. (2005). The role of the right hemisphere in processing nonsalient metaphorical meanings: Application of principal components analysis to fMRI data. Neuropsychologia, 43, 2084-2100.

Mashal, N., Faust, M., Hendler, T., \& Jung-Beeman, M. (2007). An fMRI investigation of the neural correlates underlying the processing of novel metaphoric expressions. Brain \& Language, 100, 115-126.

Mashal, N., Faust, M., Hendler, T., \& Jung-Beeman, M. (2009). An fMRI study of processing novel metaphoric sentences. Laterality, 14, 30-54.

Menenti, L., Petersson, K. M., Scheeringa, R., \& Hagoort, P. (2009). When elephants fly: Differential sensitivity of right and left inferior frontal gyri to discourse and world knowledge. Journal of Cognitive Neuroscience, 21, 2358-2368.

Nelson, D. L., McEvoy, C. L., \& Schreiber, T. A. (1998). The University of South Florida word association, rhyme, and word fragment norms. Retrieved January 2009 from www.usf.edu/ FreeAssociation.

Paivio, A., Yuille, J. C., \& Madigan, S. A. (1968). Concreteness, imagery, and meaningfulness values for 925 nouns. Journal of Experimental Psychology, 76(, Pt. 2), 1-25.

Papagno, C., \& Caporali, A. (2007). Testing idiom comprehension in aphasic patients: The effects of task and idiom type. Brain \& Language, 100, 208-220.

Papagno, C., \& Genoni, A. (2004). The role of syntactic competence in idiom comprehension: A study on aphasic patients. Journal of Neurolinguistics, 17, 371-382.

Papagno, C., Tabossi, P., Colombo, M. R., \& Zampetti, P. (2004). Idiom comprehension in aphasic patients. Brain \& Language, 89, 226-234.

Pobric, G., Mashal, N., Faust, M., \& Lavidor, M. (2008). The role of the right cerebral hemisphere in processing novel metaphoric expressions: A transcranial magnetic stimulation study. Journal of Cognitive Neuroscience, 20, 170-181.

Prat, C. S., Keller, T. A., \& Just, M. A. (2007). Individual differences in sentence comprehension: A functional magnetic resonance imaging investigation of syntactic and lexical processing demands. Journal of Cognitive Neuroscience, 19, 1950-1963.

PulVermülleR, F. (2005). Brain mechanisms linking language and action. Nature Reviews Neuroscience, 6, 576-582.

Rapp, A. M., Leube, D. T., Erb, M., Grodd, W., \& Kircher, T. T. J. (2004). Neural correlates of metaphor processing. Cognitive Brain Research, 20, 395-402.

Rapp, A. M., Leube, D. T., Erb, M., Grodd, W., \& Kircher, T. T. J. (2007). Laterality in metaphor processing: Lack of evidence from functional magnetic resonance imaging for the right hemisphere theory. Brain \& Language, 100, 142-149.

Rinaldi, M. C., Marangolo, P., \& Baldassarri, F. (2004). Metaphor comprehension in right brain-damaged patients with visuoverbal and verbal material: A dissociation (re)considered. Cortex, 40, 479-490.

Schmidt, G. L., Kranjec, A., Cardillo, E. R., \& Chatterjee, A. (2010). Beyond laterality: A critical assessment of research on the neural basis of metaphor. International Journal of Neuropsychology, 16, 1-5.

ScotT, S. K. (2004). The neural representation of concrete nouns: What's right and what's left? Trends in Cognitive Sciences, 8, 151-153.

SEARLe, J. (1979). Expression and meaning. Cambridge: Cambridge University Press.

Shibata, M., Abe, J., Terao, A., \& Miyamoto, T. (2007). Neural mechanisms involved in the comprehension of metaphoric and literal sentences: An fMRI study. Brain Research, 1166, 92-102.

Simmons, W. K., \& Barsalou, L. W. (2003). The similarity-intopography principle: Reconciling theories of conceptual deficits. Cognitive Neuropsychology, 20, 451-486. 
Sotillo, M., Carretié, L., Hinojosa, J. A., Tapia, M., Mercado, F., López-Martín, S., \& Albert, J. (2005). Neural activity associated with metaphor comprehension: Spatial analysis. Neuroscience Letters, 373, 5-9.

Stringaris, A. K., Medford, N. C., Giampietro, V., Brammer, M. J., \& DAvID, A. S. (2007). Deriving meaning: Distinct neural mechanisms for metaphoric, literal, and non-meaningful sentences. Brain \& Language, 100, 150-162.

THOMPSON-SCHILL, S. L. (2003). Neuroimaging studies of semantic memory: Inferring "how" from "where." Neuropsychologia, 41, 280-292.

Toglia, M. P., \& Battig, W. F. (1978). Handbook of semantic word norms. Hillsdale, NJ: Erlbaum.

TompKins, C. A. (1990). Knowledge and strategies for processing lexical metaphor after right or left hemisphere brain damage. Journal of Speech \& Hearing Research, 33, 307-316.

Tompkins, C. A., Boada, R., \& McGarry, K. (1992). The access and processing of familiar idioms by brain-damaged and normally aging adults. Journal of Speech \& Hearing Research, 35, 626-637.

Torreano, L. A., Cacciari, C., \& Glucksberg, S. (2005). When dogs can fly: Level of abstraction as a cue to metaphorical use of verbs. Metaphor \& Symbol, 20, 259-274.

Tranel, D., Manzel, K., Asp, E., \& Kemmerer, D. (2008). Naming dynamic and static actions: Neuropsychological evidence. Journal of Physiology, Paris, 102, 80-94.

Van Lancker, D. R., \& Kempler, D. (1987). Comprehension of familiar phrases by left- but not by right-hemisphere damaged patients. Brain \& Language, 32, 265-277.

Wallentin, M., Lund, T. E., Østergaard, S., Østergaard, L., \& RoEpstorfF, A. (2005). Motion verb sentences activate left posterior middle temporal cortex despite static context. NeuroReport, 16, 649652.

Wallentin, M., Østergaard, S., Lund, T. E., Østergaard, L., \& Roepstorff, A. (2005). Concrete spatial language: See what I mean? Brain \& Language, 92, 221-233.
WINNER, E., \& GARDNER, H. (1977). The comprehension of metaphor in brain-damaged patients. Brain, 100, 717-729.

Wu, D. H., Waller, S., \& Chatterjee, A. (2007). The functional neuroanatomy of thematic role and locative relational knowledge. Journal of Cognitive Neuroscience, 19, 1542-1555.

Yarkoni, T., Speer, N. K., Balota, D. A., McAvoy, M. P., \& Zacks, J. M. (2008). Pictures of a thousand words: Investigating the neural mechanisms of reading with extremely rapid event-related fMRI. NeuroImage, 42, 973-987.

Zaidel, E., KASHer, A., SOROKer, N., \& BAtORI, G. (2002). Effects of right and left hemisphere damage on performance of the "Right Hemisphere Communication Battery." Brain \& Language, 80, 510-535.

\section{NOTES}

1. This particular task was chosen not only because it has been used in previous metaphor research, but also because the other most commonly used task - a plausibility judgment-may not be well suited to studies involving novel metaphors. The inclusion of implausible sentences risks biasing readers away from making metaphoric interpretations of unfamiliar but interpretable metaphors. In addition, a valence judgment task enables controlling for differences in verbal processing associated with the affective content of stimuli (cf. Kutas, 2006).

2. The instructions were slightly modified directions from Paivio, Yuille, and Madigan (1968) and also very similar to those used in the two other major sources of concreteness and imageability norms in the MRC Psycholinguistic Database (i.e.; Gilhooly \& Logie, 1980; Toglia \& Battig, 1978).

\section{SUPPLEMENTAL MATERIALS}

The sentence materials for this study and the norms associated with each sentence may be downloaded from http://brm.psychonomic -journals.org/content/supplemental. 
APPENDIXA

Words Normed for Concreteness

accountant, admonishment, alibi, amused, anthology, applause, archeological, aside, assignment, ATM, babble, bankruptcy, bashful, beckoning, billboard, blast, bleat, belch, blubber, blurt, bold, braking, bully, bungee, cackle, campaign, canter, canvas, carousel, cartwheel, cathartic, celebrity, celebrity, chant, chase, chat, chatter, cheer, chime, chirp, clamber, clatter, clatter, click, clomp, cluck, collapse, colorful, comeback, comment, commotion, competitive, complaint, complicated, composition, confident, constant, controversial, coo, cooking, corporate, corrupt, couple, course, creep, curl, current, dash, declined, demo, designer, desperate, dice, dieter, disorder, disturbance, divorcee, dodge, drift, drive, drone, drummer, editorial, elitist, email, embarrassed, embarrassment, endless, environmentalist, eviction, ex, excursion, exhausting, exhibition, eyelashes, fart, feminist, fizzle, flip, flit, flop, flounder, forced, forgotten, furtive, gambler, gardener, gaze, gear, girlfriend, glance, gleeful, glide, goodbye, grasp, greeting, growl, grumble, grunt, guffaw, gurgle, haircut, handshake, hangover, headline, heartbroken, hipster, hiss, hobble, homework, hoot, hopeful, hormonal, hostess, housewife, huff, icy, ill-timed, immediate, injection, input, insistent, interjection, Internet, interviewer, irrepressible, irresistible, irritating, karate, landing, Latin, legal, leisurely, license, literary, logging, loophole, lope, lost, lurch, massage, media, mediocre, memoirs, mere, model, monk, mosey, motif, mumble, murmur, negotiations, nervous, objection, obstacle, oink, optimistic, outburst, outraged, overhead, packaging, painful, paisley, pamphlet, paperwork, parking, partnership, password, patriotic, perfect, perspective, petition, photographer, plod, plummet, poignant, polluted, popular, posture, pounce, prance, preacher, pregnancy, press, pretentious, Prius, privileged, programmer, promised, purr, rant, reception, recession, recording, rejection, relationship, relay, reproach, request, rescuer, resume, retort, revealing, romantic, romp, roommate, rousing, runner, runway, sashay, scamper, screech, screech, script, scrutiny, scurry, seizure, serenade, sexist, shameless, shipwreck, shuffle, shy, sidle, single, sip, sizzle, skater, skulk, skydive, slam-dunk, sleepwalk, slink, slogan, slouch, slurp, smirk, snarl, sneak, snicker, sniff, snigger, snore, sputter, squawk, squeal, stammer, stampede, status, steady, stir, stomp, stoplight, straggler, strategy, stroll, struggle, stutter, successful, suitor, supportive, surfer, SUV, swagger, swimmer, symptom, tacky, tailspin, take-off, tango, tattoo, teen, teenager, textbook, theater, therapy, tiptoe, totter, traipse, trajectory, trek, trickle, triumphant, trudge, t-shirt, tsunami, tug, twitch, twitter, unexpected, unpaid, urgent, valley, vocalization, wade, waiting, Wallstreet, waterfall, whimper, whine, whinny, whir, winner, word, wrecking, wrestle, wrinkled, yip, yodel

\section{APPENDIX B}

Words Normed for Auditory and Visual Imagery

argue, babble, balloon, bang, bark, belch, blast, bleat, blubber, blurt, bounce, buzz, cackle, call, canter, cartwheel, chant, charge, chat, cheer, chime, chirp, chop, chuckle, clamber, clamor, clash, clatter, click, climb, clomp, cluck, coast, collapse, coo, cough, crackle, crawl, creep, cry, dance, dart, dash, dig, dive, dodge, drift, drive, drone, drop, drum, fall, fart, fizzle, flip, flit, flop, flounder, flow, flush, fly, gasp, gesture, giggle, glide, groan, growl, grumble, grunt, guffaw, gurgle, hiss, hobble, holler, hoot, hop, howl, huff, hug, hum, hush, inch, jingle, jog, jump, knock, laugh, launch, leap, lift, limp, lope, lumber, lurch, march, moan, mosey, move, mumble, murmur, oink, plod, plow, plummet, polka, pop, pounce, prance, press, puff, pull, punch, purr, push, quack, race, rain, rant, rattle, reel, retreat, ride, roar, roll, run, sail, sashay, scamper, scream, screech, scurry, serenade, shatter, shout, shriek, shuffle, sidle, sigh, sing, sizzle, skulk, skydive, slam-dunk, slap, sleepwalk, slide, slink, slither, slouch, slurp, smash, snake, snap, snarl, sneak, sneeze, snicker, sniff, snigger, snore, snort, sob, spill, spin, splash, spring, sprint, sputter, squawk, squeal, stab, stammer, stampede, stand, stir, stomp, stream, stretch, stroll, strut, stumble, stumble, stutter, surf, surge, swagger, swarm, sweep, swim, swing, tailspin, take-off, tango, thunder, tiptoe, toss, totter, traipse, trudge, tug, twitter, voice, wade, wail, walk, waltz, wander, wave, weep, whimper, whine, whinny, whir, whirl, whisper, whistle, whoop, wiggle, wind, worm, wrestle, yawn, yell, yelp, yip, yodel, yowl, zigzag 


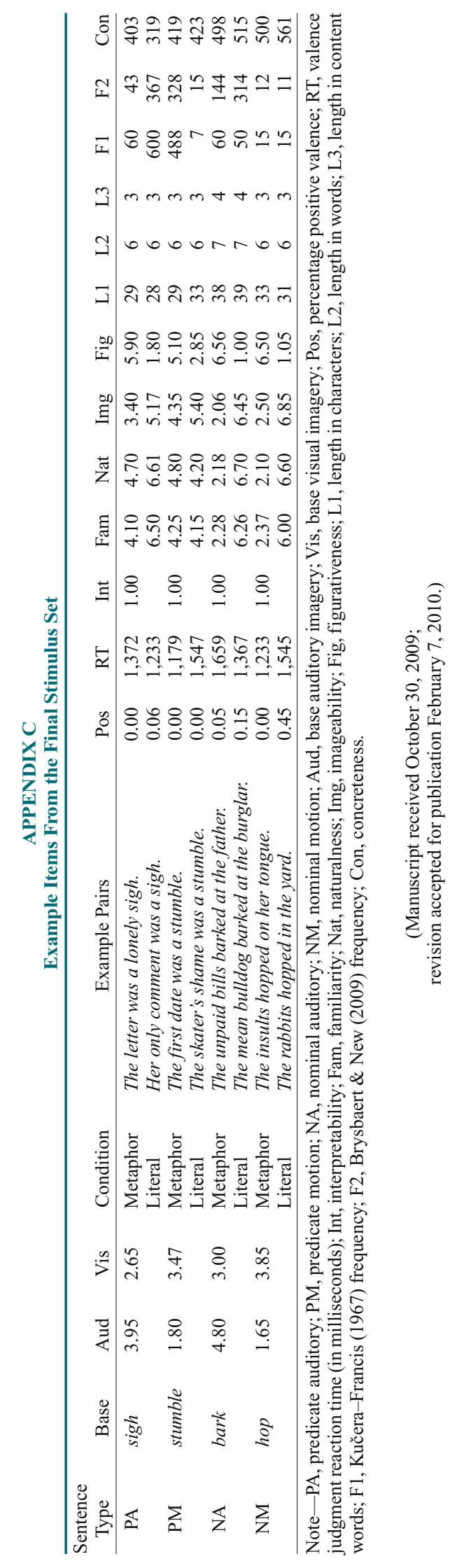

